\title{
Double Cystic Artery Originating in a Right and a Segment IV Hepatic Artery: A Case Report
}

\author{
Moon Jin Kim, M.D., Young Chul Yoon, M.D., Ph.D. \\ Department of Surgery, Incheon St. Mary's Hospital, The Catholic University of Korea, Incheon, Korea
}

\begin{abstract}
Anatomical variation of the cystic artery $(\mathrm{CA})$ is frequently observed. However, a CA originating in a segment IV hepatic artery (HA) has been rarely reported. We report double CA originating in a right segment IV HA detected during laparoscopic cholecystectomy (LC). A 67-year-old man underwent LC for symptomatic gallstones. We ligated and divided the cystic duct initially, and performed a procedure similar to the management of CA in the hepatobiliary triangle. In contrast to the other cases, the falciform ligament was attached to gallbladder. Severe arterial bleeding was observed during the dissection. We dissected the bleeding site and found another CA for ligation. A preoperative abdominal computed tomography (CT) scan confirmed a CA originating from a segment IV HA. The patient was discharged without any events the next day. In conclusion, we report a CA originating in segment IV HA. A falciform ligament attached to gallbladder suggests the unusual CA.
\end{abstract}

Keywords: Cystic artery, Anatomic variation, Cholecystectomy
Received April 29, 2019

Revised May 18, 2019

Accepted June 18, 2019

\section{Corresponding author}

Young Chul Yoon

Department of Surgery, Incheon

St. Mary's Hospital, The Catholic

University of Korea, 56 Dongsu-ro,

Bupyung-gu, Incheon 21431, Korea

Tel: $+82-32-280-5862$

Fax: +82-32-280-5988

E-mail: k07yyc@catholic.ac.kr

ORCID:

https://orcid.org/0000-0002-5341-2370

Copyright @ 2020 The Journal of Minimally Invasive Surgery. All rights reserved.

\section{INTRODUCTION}

In laparoscopic cholecystectomy (LC), surgeons cannot detect the pulse of arterial blood vessels during the surgery. Therefore, it is important to understand the anatomy of blood vessels before and during the operation. Despite variations in the cystic artery (CA), its location in the hepatobiliary triangle (known as the Calot's triangle) during surgery is not considered a serious challenge. However, the origin of the CA in an unusual site during surgery may confuse the surgeon. To the best of my knowledge, only 2 cases of CA originating in the segment IV hepatic artery (HA) have been published. ${ }^{1}$ How $^{-}$ ever, this article did not provide any evidence of $\mathrm{CA}$ originated in the segment IV HA. Therefore, we report a CA originating in the segment IV HA with evidence confirming bleeding from an unusual site during surgery.

\section{CASE REPORT}

A 67-year-old man underwent LC with symptomatic gallstones. No abnormal findings were detected in the abdominal cavity except for the falciform ligament attached to the gallbladder (Fig. 1A). As usual, we ligated and divided the cystic duct similar to the procedure used to manage CA (Fig. 1B). Arterial bleeding was observed during the dissection of the falciform ligament from the gallbladder (Fig. 1C). We identified and located another CA from the bleeding site (Fig. 1D). Following the surgery, we reviewed the findings from preoperative abdominal computed tomography and found two CA, including one originating in the right $\mathrm{HA}$ and another in the segment IV HA (Fig. 2). The patient was discharged the day after surgery without any adverse events.

This case report was approved by the Institutional Review 

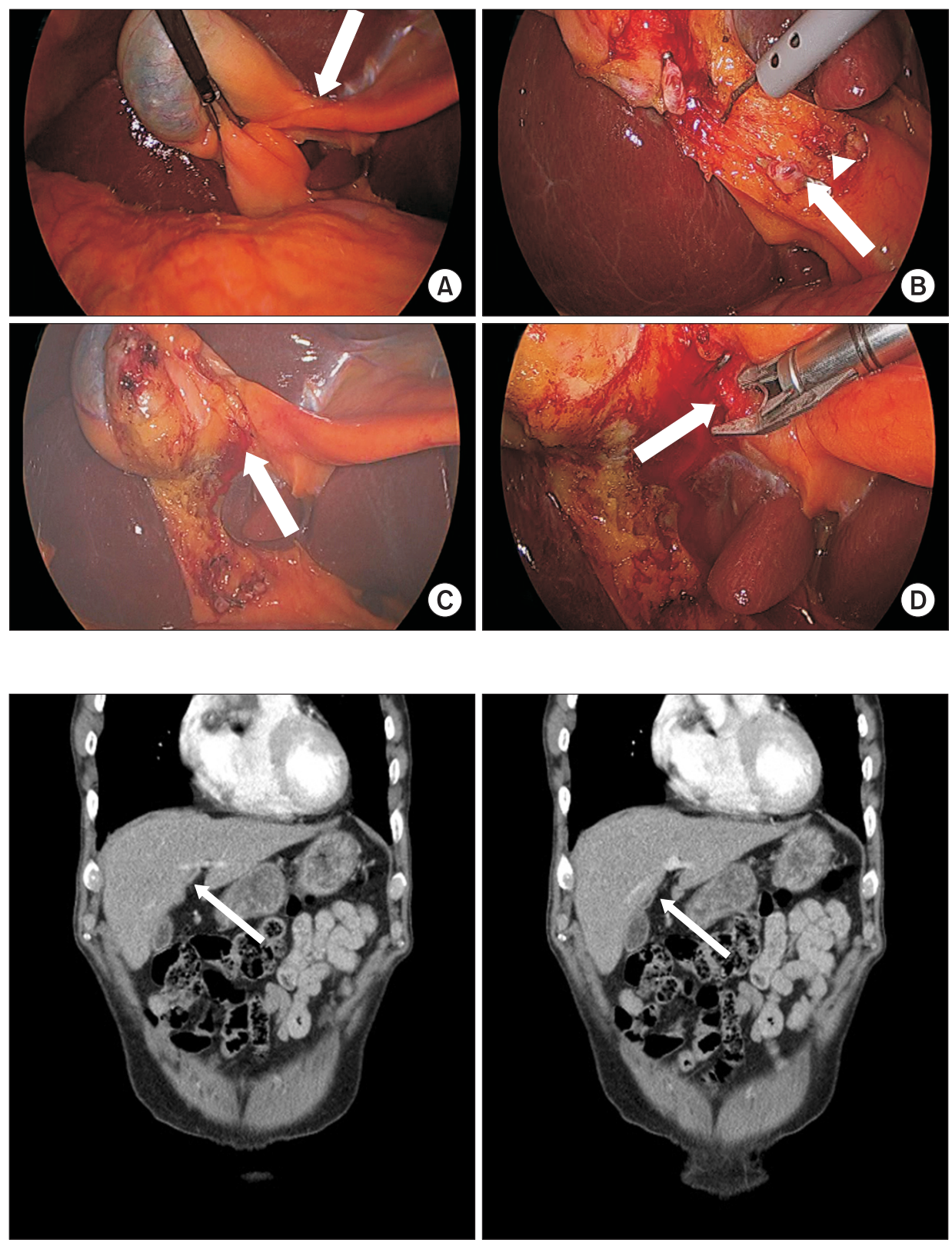

Fig. 1. Intraoperative findings during surgery. (A) Falciform ligament is attached to gallbladder (arrow). (B) Cystic duct stump (arrow) and cystic artery stump (arrow head) after resection. (C) Arterial bleeding during dissection of the falciform ligament from gallbladder (arrow). (D) Identifying and ligation of cystic artery (arrow).
Fig. 2. Cystic artery originated from segment IV hepatic artery (arrow).
Board of the Incheon St. Mary's Hospital. The patient provided written informed consent to participate, and for publication.

\section{DISCUSSION}

In most cases, bile duct injury is the most important indication for surgical attention during LC. However, since CA injury and bleeding may trigger open conversion, inevitable injury to the surrounding bile duct or HA, delayed bleeding and mortality, surgeons should investigate further. Several anatomic variations of the CAs exist. Approximately $80 \%$ of the $\mathrm{CAs}$ originate in the right $\mathrm{HA}$, and the remainder arise in the common HA, left HA, replaced right HA, accessory left HA, gastroduodenal artery, superior pancreaticoduodenal artery, celiac artery and segments IV, V, VI, and VIII HAs. ${ }^{1-9}$ Approximately $9 \%$ carry more than one CA. More than $80 \%$ of the CA is observed in the hepatobiliary triangle. ${ }^{4}$ Therefore, if the inflammation is not severe, the surgeon usually needs to be careful when dissecting the surrounding tissue around hepatobiliary triangle. If the CA arising outside the hepatobiliary triangle, it usually passes ventral to the $\mathrm{CBD}$ and in some cases it may even be inferior to the cystic duct, thus becoming the first structure encountered in dissection of the inferior border of the hepatobiliary triangle. ${ }^{10}$

We performed 4326 cases of cholecystectomy at our hospital from February 2011 to December 2018. The two cases $(0.05 \%)$ 
of open conversion following CA injury and the single case $(0.02 \%)$ of delayed bleeding were associated with severe inflammation. Therefore, experienced surgeons do not need to worry excessively about the anatomical variations of the CA except in cases of severe inflammation. Further, during LC, dissection of a limited field is magnified on the video monitor to provide a detailed knowledge of the possible anatomical variation involving the $\mathrm{CA}$ and its branches to guide surgical intervention. However, we eventually found an anatomical variation of CA originating in segment IV HA during LC, which confused us. Probably, this case represents the first unusual anatomical variation of its kind, never seen before.

In conclusion, a falciform ligament attached to the gallbladder during cholecystectomy should be considered as an unusual case of CA.

\section{AVAILABILITY OF DATA AND MATERIALS}

The data used to support the conclusions made in this case report are all included within the article.

\section{ORCID}

Moon Jin Kim, https://orcid.org/0000-0002-5404-3431

Young Chul Yoon, https://orcid.org/0000-0002-5341-2370

\section{AUTHORS' CONTRIBUTIONS}

MJK drafted the manuscript and collected the references. YCY performed the surgery, designed the study, and approved the final draft.

\section{CONFLICT OF INTEREST}

None.

\section{FUNDING}

None.

\section{ACKNOWLEDGMENTS}

None.

\section{REFERENCES}

1) Mlakar B, Gadzijev EM, Ravnik D, Hribernik M. Anatomical variations of the cystic artery. Eur J Morphol 2003;41:31-34.

2) Komatsu $\mathrm{T}$, Matsui $\mathrm{O}$, Kadoya M, Yoshikawa J, Gabata $\mathrm{T}$, Takashima T. Cystic artery origin of the segment $\mathrm{V}$ hepatic artery. Cardiovasc Intervent Radiol 1999;22:165-167.

3) Browne EZ. Variations in origin and course of the hepatic artery and its branches: Importance from surgical viewpoint. Surgery 1940;8:424-445.

4) Andall RG, Matusz P, du Plessis M, Ward R, Tubbs RS, Loukas M. The clinical anatomy of cystic artery variations: a review of over 9800 cases. Surg Radiol Anat 2016;38:529-539.

5) Chen TH, Shyu JF, Chen CH, et al. Variations of the cystic artery in Chinese adults. Surg Laparosc Endosc Percutan Tech 2000;10: 154-157.

6) Sarkar AK, Roy TS. Anatomy of the cystic artery arising from the gastroduodenal artery and its choledochal branch--a case report. J Anat 2000;197 Pt 3:503-506.

7) McNulty JG. Total anomalous arterial supply to the liver and gallbladder from the gastroduodenal artery: a case report. Surg Radiol Anat 2000;22:123-124.

8) Molmenti EP, Pinto PA, Klein J, Klein AS. Normal and variant arterial supply of the liver and gallbladder. Pediatr Transplant 2003;7:80-82.

9) Price P, Holden C. Anatomic variance in the cholecystic blood supply: a case report. Am Surg 1993;59:278-280.

10) Hugh TB, Kelly MD, Li B. Laparoscopic anatomy of the cystic artery. Am J Surg 1992;163:593-595. 